\title{
Modeling of agarwood oil compounds based on linear regression and ANN for oil quality classification
}

\author{
Noratikah Zawani Mahabob', Zakiah Mohd Yusoff', Aqib Fawwaz Mohd Amidon³, \\ Nurlaila Ismail ${ }^{4}$, Mohd Nasir Taib ${ }^{5}$ \\ ${ }^{1,3,4}$ College of Engineering, Universiti Teknologi MARA, Shah Alam, Selangor, Malaysia \\ ${ }^{2}$ College of Engineering, Universiti Teknologi MARA, Cawangan Johor, Kampus Pasir Gudang, Malaysia \\ ${ }^{5}$ Malaysia Institute of Transport (MITRANS), Universiti Teknologi MARA, Shah Alam, Selangor, Malaysia
}

\begin{tabular}{l}
\hline Article Info \\
\hline Article history: \\
Received Dec 19, 2020 \\
Revised Apr 14, 2021 \\
Accepted Apr 26, 2021 \\
\hline
\end{tabular}

\section{Keywords:}

Agarwood oil

Levenberg marquardt Multilayer perceptron Resilient backpropagation Scale conjugate gradient Stepwise regression

\begin{abstract}
Agarwood oil is in increasing demand in Malaysia throughout the world for use in incense, traditional medicine, and perfumes. However, there is still no standardized grading method for agarwood oil. It is vital to grade agarwood oil into high and low quality so that both qualities can be properly differentiated. In the present study, data were obtained from the Forest Research Institute Malaysia (FRIM), Selangor Malaysia and Bioaromatic Research Centre of Excellence (BARCE), Universiti Malaysia Pahang (UMP). The work involves the data from a previous researcher. As a part of on-going research, the stepwise linear regression and multilayer perceptron have been proposed for grading agarwood oil. The output features of the stepwise regression were the input features for modeling agarwood oil in a multilayer perceptron (MLP) network. A three layer MLP with 10 hidden neurons was used with three different training algorithms, namely resilient backpropagation (RBP), levenberg marquardt (LM) and scaled-conjugate gradient (SCG). All analytical work was performed using MATLAB software version R2017a. It was found that one hidden neuron in LM algorithm performed the most accurate result in the classification of agarwood oil with the lowest mean squared error (MSE) as compared to SCG and RBP algorithms. The findings in this research will be a benefit for future works of agarwood oil research areas, especially in terms of oil quality classification.
\end{abstract}

This is an open access article under the CC BY-SA license.

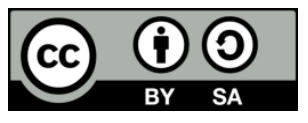

\section{Corresponding Author:}

Zakiah Mohd Yusoff

Faculty of Electrical Engineering

Universiti Teknologi MARA (UiTM)

Cawangan Johor, Kampus Pasir Gudang, Johor, Malaysia

Email: zakiah9018@uitm.edu.my

\section{INTRODUCTION}

Essential oils have highly concentrated compounds and produce aromatic smells. They are extracted from plants as secondary metabolites [1], [2]. Agarwood oil is a well-known essential oil extracted from agarwood trees that belong to the genus Aquiliria Malaccensis of the plant family Thymelaeaceae [3]. Agarwood is resin-impregnated heartwood. All parts of the agarwood plant has its own use [4]. For example, tree trunks and branches can produce quality powder and in addition the essential oils produce from the stems [4]. Agarwood is used in incense, perfumery, medicine and ceremonies by numerous cultures and religious [3], [5], [6]. To obtain a good quality of agarwood oil, it must be through a grading process. Previously, agarwood oil has been graded according to its physical properties such as color intensity, density, and odor as well as by using human sensory panels. However, the limitation in terms of subjectivity, poor reproducibility and, also time 
consumption are the factor that considering the technique is not efficient to be used [3], [7], [8]. Besides, dealing with a bulk of samples and continuous production in a continuous period of time can cause fatigue to the human nose [3].

Essential oil quality classification can be performed based on chemical profiles, so that essential oil can be accurately classified according to their respective classes (high or low grade). Researchers now use a modern techniques for classifying agarwood oil using machine learning techniques such as artificial neural network (ANN), support vector machine (SVM), multilayer perceptron (MLP) and also various analysis techniques [7], [9]-[13]. An existing study applied ANN technique for grading agarwood oil [10]. The researcher builds two model of ANN, where the first model with 16 samples of data and another model with 90 samples (16 original samples x 5 repetitions of synthetic data). The objective of the researcher is to observe the performance of ANN within large samples of data and the results found that ANN with large samples of data performed in higher accuracy [10]. Next, a method of SVM is used in grading agarwood oil by using two kernel parameters which are multilayer perceptron (MLP) and radial basis function (RBF) [14]. The scaled conjugate gradient (SCG) as MLP algorithm has been successfully applied in grading agarwood oil [7]. The samples data are fed into MLP and the modelling using SCG with 10 hidden neurons and data division of 70\%:15\%:15 for training, validation and testing. The accuracy and MSE value is taken as consideration for SCG performance. Furthermore, a researcher has been done a study on agarwood oil using ANN and analyzes chemical compounds using GC-MS and SPME method [15]. The findings of the study state that there are few compounds should be call attention for high grade quality agarwood oil and can be used as a future benchmark in classifying agarwood oil. The compounds are aromadendran, 10-epi-eudesmol, $\beta$-agarofuran, $\alpha$-agarofuran and $\beta$-eudesmol [15].

Currently, the MLP network has widely used among the researcher in any areas of studies such as in grading the essential oil, pattern recognition, oil industry and many others [16]-[23]. MLP successfully implement in estimating the extraction yield on Oregano and Valerian essential oil [16], [17]. Researcher [17] used training algorithms; SCG, RBP, LM and Gradient Descent, while researcher [16] only used LM algorithm. The only similarities in both research studies are the results obtained showed that LM algorithm performed good accuracy with minimum error. Researcher [18] successfully implemented MLP to detect infant hypothyroidism using cry signal that extracts using MFCC analysis. Different number of hidden neurons and the number of coefficients are varied in this experiment as well as a scaled conjugate gradient (SCG) as training algorithm. The output obtained concluded that the lowest MSE and highest accuracy performed at hidden neurons 15 with the 20 feature coefficients [18]. Based on existing work in [19] and [20], the MLP network is used in pattern recognition in which recognize 18 leaves images by classifying the defected and un-defected leaves and classifying the resume according to the job specification by word recognition.

In this research study, a new engineering approach technique is proposed using Stepwise Linear Regression as statistical analysis technique to predict the relationship between the input and output of agarwood oil. The MLP implemented with the training algorithms; resilient backpropagation (RBP), scaled conjugate gradient (SCG) and levenberg marquardt (LM) as classifiers to classify agarwood oil into high and low quality. The performances of each training algorithm are compared using a Confusion Matrix and mean square error (MSE). The objective of this research study is to predict the compounds of agarwood oil that gives the major factors in the quality of agarwood oil using stepwise regression and after that to validate the selected compounds using training algorithms of MLP for classification.

\section{RESEARCH METHOD}

\subsection{Data collections}

A total of 96 samples was obtained by the previous researcher for the extraction of agarwood oil from Forest Research Institute Malaysia (FRIM) and BioAromatic Research Centre of Excellence (BARCE), Universiti Malaysia Pahang (UMP) [15]. From 96 samples, there were 78 samples from high quality agarwood oil and 18 samples were from low quality agarwood oil. The data consists of seven inputs which indicate the seven selected significant compounds known as $\mathrm{C} 1=\beta$-agarofuran, $\mathrm{C} 2=\alpha$-agarofuran, $\mathrm{C} 3=10$-epi$\Upsilon$-eudesmol, C4= $\Upsilon$-Eudesmol, C5=Longifolol, C6=Hexadecanol and C7=Eudesmol [15]. The output was the quality of agarwood oil, with $2=$ low quality and $1=$ high quality.

\subsection{Stepwise regression}

Firstly, the method started with stepwise regression. Stepwise multivariable regression has been selected for this study because there was more than one independent variables of agarwood oil compounds used in this research study. Stepwise regression was established as shown in Figure 1, the flowchart of stepwise method: 


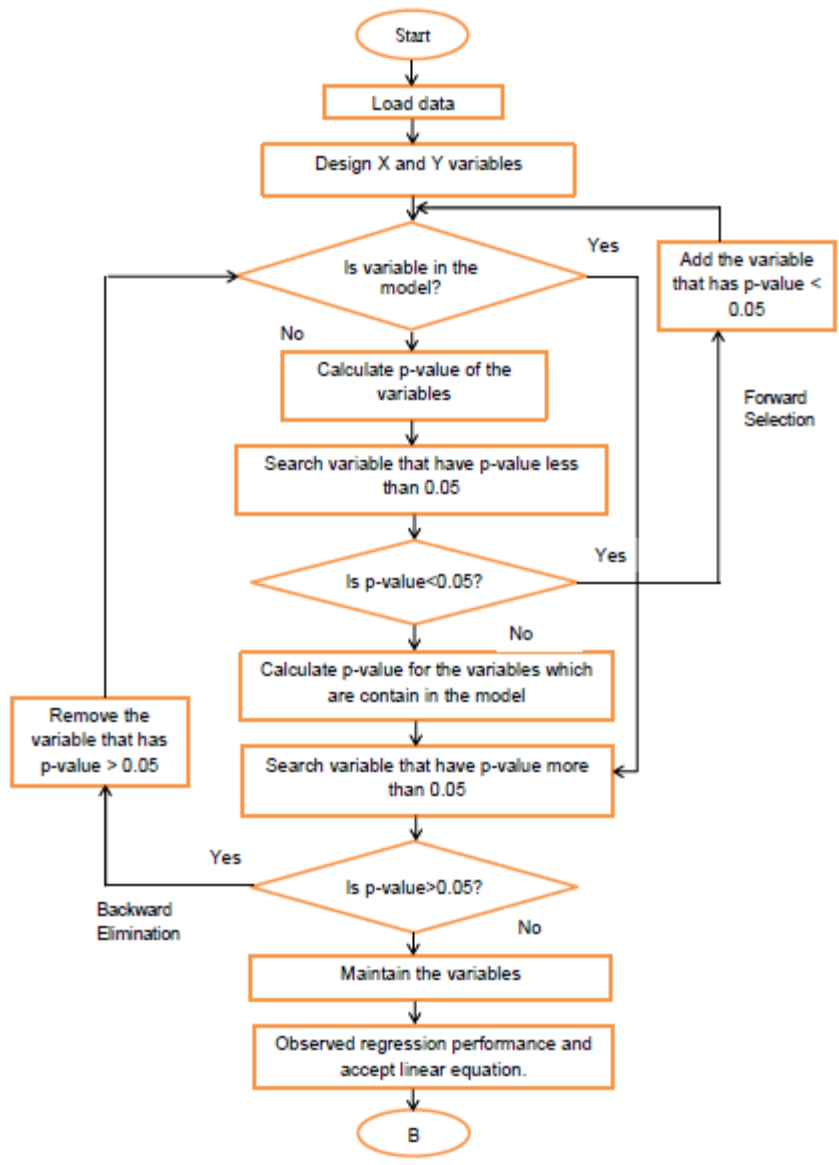

Figure 1. Detail experiment of stepwise regression method

Step 1: Design variables

The sample data were loaded into the MATLAB version R2017a. Then, the data were divided into two classes; independent $(X)$ and dependent variables $(Y)$. The $X$ variables were $X_{1}=\beta$-agarofuran, $X_{2}=\alpha$ agarofuran, $X_{3}=10$-epi- $\Upsilon$-eudesmol, $X_{4}=\Upsilon$-Eudesmol, $X_{5}=$ Longifolol, $X_{6}=$ Hexadecanol and $X_{7}=$ Eudesmol according to seven inputs of selected significant compounds. The $\mathrm{Y}$ variables were set as agarwood oil quality consist of high and low quality.

Step 2: Train the dataset

The data were then trained by stepwise regression. Stepwise regression includes the forward selection and backward elimination method. In this experiment, the significance value of alpha, $\alpha$ was set to 0.05 or $5 \%$ as recommended by existing study in [24].

Step 3: Forward selection

Starting with the empty variables, stepwise calculates the $\mathrm{p}$-value of the $\mathrm{X}$ variables. The $\mathrm{p}$-value of each $\mathrm{X}$ variables was observed step-by-step and if the $\mathrm{p}$-value was less than 0.05 , the $\mathrm{X}$ variable was added to the model; otherwise, the $X$ variable was not be added and forward selection continued searching for another $\mathrm{X}$ variable that was not in the model until the significant variables were included.

Step 4: Backward elimination

Next, the backward elimination observed the p-value of $X$ variables that are already in the model. The $\mathrm{X}$ variables will be removed from the model if the $\mathrm{p}$-value was more than 0.05 ; otherwise, the variable would be maintained in the model. The process of adding and removing the $\mathrm{X}$ variables was done repeatedly and automatically by MATLAB until finding all X variables with the strongest effects on the agarwood oil.

Step 5: Statistical analysis and interpret the output

The model of stepwise multiple regressions in this research study can be represented as $\mathrm{Y}=\mathrm{m}_{1} \mathrm{X}_{1}+$ $m_{2} X_{2}+m_{3} X_{3}+m_{4} X_{4}+m_{5} X_{5}+m_{6} X_{6}+m_{7} X_{7}+C$, where $Y$ is the dependent variable (quality of agarwood oil), $X_{1}$ until $X_{7}$ are the independent variables of agarwood oil, and $m_{1}$ to $m_{7}$ are the coefficient of each independent variables. The $C$ indicates the error term [25], [26]. Next, the results of stepwise regression for this experiment were generated by MATLAB within some parameters, such as the root mean squared error 
(RMSE), coefficient of determination $R^{2}$, adjusted coefficient of determination $R^{2}$ (Adjst $R^{2}$ ), the F-statistics and the overall $\mathrm{p}$-value of the model. The percentage of variability response of dependent variables was determined by the correlation of determination $R^{2}$ and adjusted $R^{2}$ and the equations were as shown in (1) and (2). The root mean square error (RMSE) was the estimation of the standard deviation of the error distribution and calculated using (3). SSE was the sum of squared errors, SSR was the sum of squared regression and SST was the sum of squared total.

$$
\begin{aligned}
& \text { Coefficient of determination, } R^{2}=\frac{S S R}{S S T}=1-\frac{S S E}{S S T} \\
& \text { Adjusted } R^{2}=1-\left(\frac{P-1}{P-Q}\right) x \frac{S S E}{S S T} \\
& R M S E=\sqrt{\frac{S S E}{D O F}}
\end{aligned}
$$

\subsection{ANN modeling}

From the Figure 2, the process continued from stepwise regression. Firstly, the output features from stepwise regression were set as the input feature for MLP network classification for validation. The modeling of agarwood oil data in MLP used pattern recognition network (patternet) function in MATLAB R2017a. Next, the project continued with the data pre-processing, which the data consists of data normalization, data randomization and data division. The data division was divided into three groups; training, validation and testing, with ratios of $70 \%: 15 \%: 15 \%$ respectively. The method then continued to train and classify the dataset using MLP training algorithms. In this stage, the training algorithms were varied using three different algorithms including resilient backpropagation (RBP), scaled-conjugate gradient (SCG) and levenberg marquardt (LM). The number of hidden neurons was set to 10 neurons in a single hidden layer. The activation functions used in the MLP network model were the sigmoid function for the hidden layer and log sigmoid function for the output layer. After training, the dataset were validated and tested for further performance. The performance of this classification was evaluated using confusion matrix which consists of accuracy, sensitivity, specificity and precision. Additionally, the training was done repeatedly in order to obtain the desired mean-squared error (MSE) value in each of hidden neurons and training algorithms. Table 1 shows the confusion matrix used in the MLP modeling to describe the classification performance of agarwood oil.

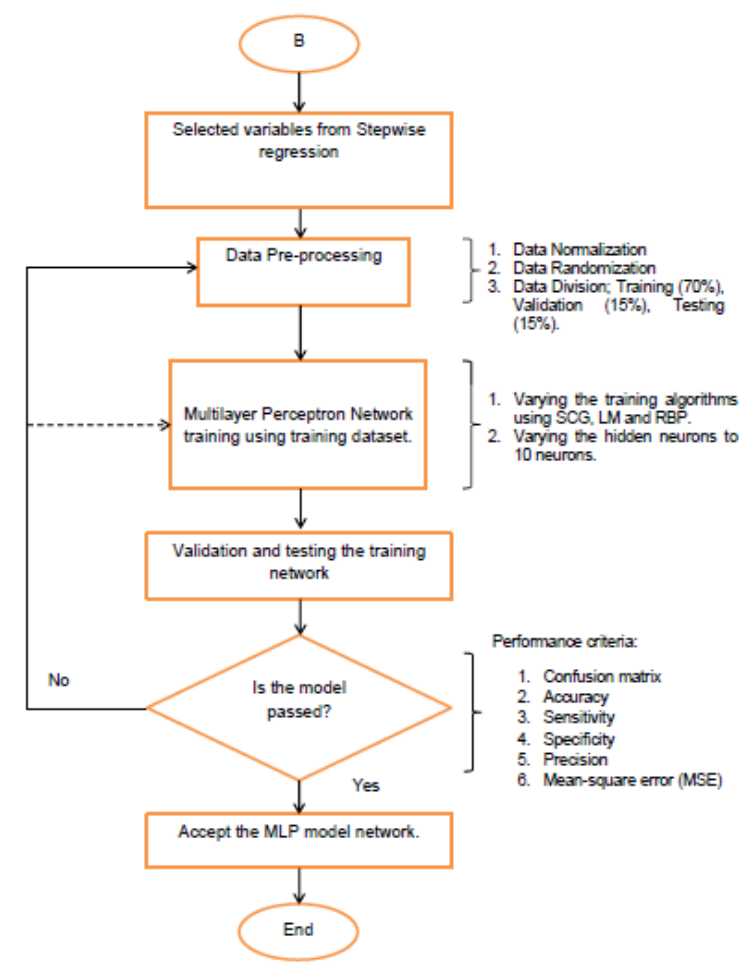

Figure 2. Detail experiment of MLP network 
Table 1. Confusion matrix

\begin{tabular}{ccc}
\hline Data Category & Category as low quality as positive & Category as high quality as negative \\
\hline Low & $(\mathrm{ep})$ & $(\mathrm{sn})$ \\
High & $(\mathrm{sp})$ & $(\mathrm{en})$ \\
\hline$e p$ is the number of accurately classified to low category; en is the number of accurately classified to high category;
\end{tabular}

$s p$ is inaccurately classified to high category; $s n$ is inaccurately classified to low category.

The equations for each performance criteria are provided below [27]. The accuracy, ACRY as in (4) is defined the overall effectiveness of a classifier:

$$
A C R Y=\frac{e p+e n}{e p+s n+s p+e n} x 100
$$

The capability of a classifier to classify the low quality group is defined as the sensitivity, STVY. Thus the interpretation for sensitivity (5) is as follows:

$$
S T V Y=\frac{e p}{e p+s n} x 100
$$

The specificity, SPCT is interpreted as practicable with the partitioned detects negative tag:

$$
S P C T=\frac{e n}{s p+e n} x 100
$$

The precision, PRCS is the class agreement of the data labels with the positive labels given by the classifier.

$$
P R C S=\frac{e p}{e p+s p} x 100
$$

\section{RESULTS AND DISCUSSION}

\subsection{Stepwise regression}

Table 2 shows the four compounds selected by stepwise regression that are significant to the model. The compounds are $\mathrm{X}_{1}=\beta$-agarofuran, $\mathrm{X}_{4}=\Upsilon$-Eudesmol, $\mathrm{X}_{5}=$ Longifolol, and $\mathrm{X}_{7}=$ Eudesmol. All independent variables were selected by forward selection according to the $\mathrm{p}$-value less than $5 \%$ significance level. These four compounds are only the major factors in agarwood oil quality. After that, MATLAB has generated an estimation of predicted output for agarwood oil as calculated and tabulated on Table 3. From the estimate value coefficients, a linear model was developed using the following stepwise multivariable equation:

$$
\begin{aligned}
& Y=X_{1}+X_{4}+X_{5}+X_{7}+C \\
& Y=1.7337+0.031742 X_{1}+0.021556 X_{4}+0.10766 X_{5}-0.25592 X_{7}
\end{aligned}
$$

The output of stepwise regression has been summarized and tabulated in Table 4. The RMSE value was 0.0224 with the value of $\mathrm{R}^{2}$ and $\mathrm{R}^{2}$ Adj were $68.7 \%$ and $67.4 \%$ respectively. The overall $\mathrm{p}$-value for the F-test was $3.4 \times 10^{-22}$ and the significant relationship of response and predictor variables in terms of F-statistics was 50 .

Table 2. Stepwise output

\begin{tabular}{ccc}
\hline Variables & F-statistics & P-value \\
\hline $\mathrm{X}_{1}$ & 6.3779 & 0.013285 \\
$\mathrm{X}_{4}$ & 17.6535 & $6.12647 \mathrm{e}-05$ \\
$\mathrm{X}_{5}$ & 33.5034 & $9.54666 \mathrm{e}-08$ \\
$\mathrm{X}_{7}$ & 79.3196 & $3.88972 \mathrm{e}-14$ \\
\hline
\end{tabular}

Table 3. Estimate coefficients

\begin{tabular}{ccccc}
\hline & Estimate value & Standard error (SE) & t-statistics & P-value \\
\hline Intercept & 1.7337 & 0.048005 & 36.115 & $9.7577 \times 10^{-56}$ \\
$\mathrm{X}_{1}$ & 0.031742 & 0.012569 & 2.5255 & 0.013285 \\
$\mathrm{X}_{4}$ & 0.021556 & 0.0049152 & 4.3857 & $3.1006 \times 10^{-5}$ \\
$\mathrm{X}_{5}$ & 0.10766 & 0.020186 & 5.3331 & $6.9926 \times 10^{-7}$ \\
$\mathrm{X}_{7}$ & -0.25592 & 0.032819 & -7.7981 & $1.0008 \times 10^{-11}$ \\
\hline
\end{tabular}


Table 4. Summary output of stepwise regression

\begin{tabular}{cc}
\hline Parameter & Value \\
\hline RMSE & 0.0224 \\
$\mathrm{R}^{2}$ & 0.687 \\
$\mathrm{R}^{2}$ Adj & 0.674 \\
P-value & $3.4 \times 10^{-22}$ \\
F-statistics & 50 \\
\hline
\end{tabular}

\subsection{MLP network}

The four compounds selected from stepwise method were fed into the MLP network model as the input features. The compounds were $\mathrm{X}_{1}=\beta$-agarofuran, $\mathrm{X}_{4}=\Upsilon$-Eudesmol, $\mathrm{X}_{5}=$ Longifolol and $\mathrm{X}_{7}=$ Eudesmol. The results of accuracy and MSE for each training algorithms have been tabulated in Tables 5-7. The results show that the training accuracy for all algorithms was varied from $86.8 \%$ to $100 \%$, while the validation accuracy varied from $92.9 \%$ to $100 \%$. The testing accuracy varied from $85.7 \%$ to $100 \%$.

Table 5. Training dataset using the SCG algorithm

\begin{tabular}{ccccc}
\hline Hidden neurons & \multicolumn{3}{c}{ Accuracy (\%) } & Mean Square Error (MSE) \\
& Training & Validation & Testing & \\
\hline$* \mathbf{1}$ & $\mathbf{9 2 . 6}$ & $\mathbf{1 0 0}$ & $\mathbf{1 0 0}$ & $\mathbf{0 . 0 4 4 6}$ \\
2 & 95.6 & 100 & 92.9 & 0.0324 \\
3 & 97.1 & 92.9 & 85.7 & 0.0259 \\
4 & 97.1 & 92.9 & 85.7 & 0.0247 \\
5 & 94.1 & 100 & 85.7 & 0.0291 \\
6 & 95.6 & 92.9 & 92.9 & 0.0326 \\
7 & 94.1 & 92.9 & 92.9 & 0.0296 \\
8 & 91.2 & 100 & 92.9 & 0.0343 \\
9 & 92.6 & 100 & 100 & 0.0385 \\
10 & 94.1 & 100 & 85.7 & 0.0364 \\
\hline *best neuron in the SCG algorithm &
\end{tabular}

Table 6. Training dataset using the LM algorithm

\begin{tabular}{|c|c|c|c|c|}
\hline \multirow[t]{2}{*}{ Hidden neurons } & \multicolumn{3}{|c|}{ Accuracy $(\%)$} & \multirow[t]{2}{*}{ Mean Square Error (MSE) } \\
\hline & Training & Validation & Testing & \\
\hline$* 1$ & 92.6 & 100 & 100 & 0.0384 \\
\hline 2 & 95.6 & 92.9 & 100 & 0.0271 \\
\hline 3 & 98.5 & 100 & 85.7 & 0.0134 \\
\hline 4 & 98.5 & 100 & 78.6 & 0.0149 \\
\hline 5 & 97.1 & 100 & 78.6 & 0.0145 \\
\hline 6 & 94.1 & 92.9 & 92.9 & 0.0316 \\
\hline 7 & 94.1 & 92.9 & 92.9 & 0.0276 \\
\hline 8 & 92.6 & 100 & 92.9 & 0.0318 \\
\hline 9 & 95.6 & 100 & 100 & 0.0341 \\
\hline 10 & 94.1 & 100 & 85.7 & 0.0314 \\
\hline
\end{tabular}

Table 7. Training dataset using the RBP algorithm

\begin{tabular}{|c|c|c|c|c|}
\hline \multirow[t]{2}{*}{ Hidden neurons } & \multicolumn{3}{|c|}{ Accuracy (\%) } & \multirow[t]{2}{*}{ Mean Square Error (MSE) } \\
\hline & Training & Validation & Testing & \\
\hline$* 1$ & 86.8 & 100 & 100 & 0.0468 \\
\hline 2 & 92.6 & 92.9 & 92.9 & 0.0345 \\
\hline 3 & 95.6 & 100 & 85.7 & 0.0262 \\
\hline 4 & 95.6 & 92.9 & 85.7 & 0.0265 \\
\hline 5 & 95.6 & 100 & 85.7 & 0.0299 \\
\hline 6 & 92.6 & 92.9 & 92.9 & 0.0339 \\
\hline 7 & 92.6 & 100 & 92.9 & 0.0389 \\
\hline 8 & 92.6 & 100 & 92.9 & 0.0338 \\
\hline 9 & 89.7 & 100 & 100 & 0.0393 \\
\hline 10 & 94.1 & 100 & 85.7 & 0.0324 \\
\hline
\end{tabular}

*best neuron in the RBP algorithms

From the Tables 5-7, the one hidden neuron in each algorithm was chosen as the best neuron for the classification of agarwood oil into high and low quality categories. The factor of choosing one hidden neuron as the best neuron was the accuracy value achieved accurately more than $80 \%$ with minimum MSE value at 
the early stage of training. Also, one hidden neuron is sufficient to avoid long computational time and overfitting problems [17], [18]. The results of MSE for each hidden neuron for all training algorithms shared the same average value. Firstly, for the SCG obtained good accuracy at the early stage of training with the value are greater than $90 \%$ accuracy and the rest $100 \%$ for validation and testing with the MSE of 0.0446 . The accuracy results obtained by LM algorithms were the same as those of SCG in all datasets, with the MSE value of 0.0384 . The accuracy results of RBP reached greater than $80 \%$ for training and $100 \%$ for validation and testing with MSE value of 0.0468. In the Figure 3, the graph pattern shows that the MSE value at one hidden neuron for SCG, LM and RBP was the highest which the value are 0.0446, 0.0384 and 0.0468 respectively. The high value of MSE at the initial stage of training is due to the initial adjustment of weight, thus producing the significantly different outputs from the actual data [9]. However, the increasing number of hidden neurons made the MSE value decrease as the weights network training became more stable [9].

MSE vs. Number of Hidden Neurons in SCG, LM and RBP Algorithms

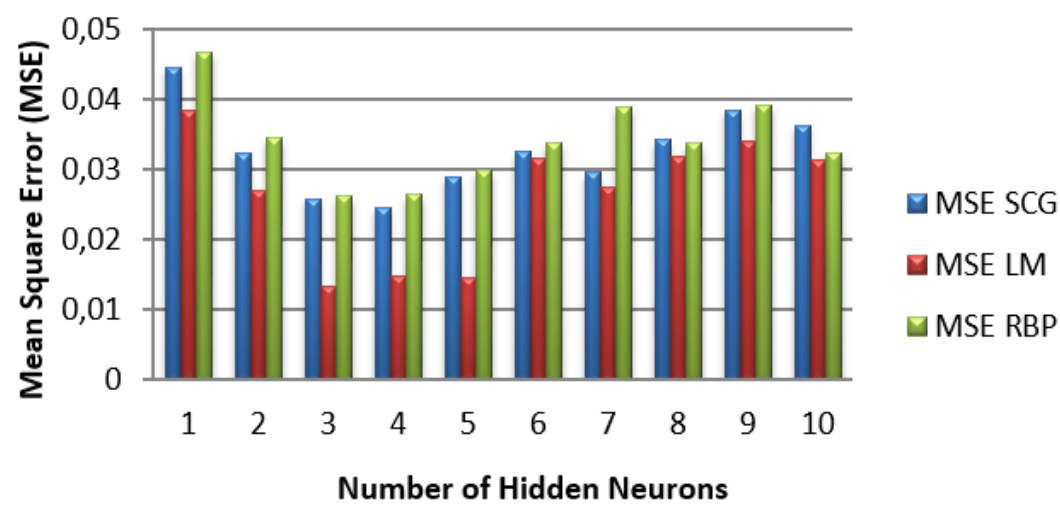

Figure 3. MSE vs. Number of hidden neurons using training algorithms

Table 8 summarizes the final design parameter of one hidden neuron in each training algorithm. When comparing the MSE value at one hidden neuron in SCG, LM and RBP, the LM algorithm outperformed others. The MSE value of the LM algorithm in one hidden neuron was the lowest compared to SCG and RBP with the value 0.0384 while SCG have MSE value with 0.0446 and MSE value of RBP is 0.0468. Obviously, LM was the best algorithm for agarwood oil classification. This proved that LM was the most capable in approaching the direction of steepest descent in providing the lowest the sum of squared errors. These finding indicate that SCG was fast in term of computational time, but greater error compare to LM.

Table 9 shows the confusion matrix of training dataset in one hidden neuron in LM algorithm. For sixty eight training numbers, the predicted class has successfully predicted seventeen numbers to low quality class and fifty one numbers to high quality class. Table 10 shows the results of the LM algorithm for training classification performance through a confusion matrix. The accuracy was $92.6 \%$, the sensitivity was $76.5 \%$, and the specificity and precision were both $98 \%$ and $92.9 \%$ respectively.

$\underline{\text { Table 8. Final design parameter of each training algorithm }}$

\begin{tabular}{cccc}
\hline Parameter & \multicolumn{3}{c}{ Training Algorithms } \\
& SCG & *LM & RBP \\
\hline Number of input neurons & 4 & $\mathbf{4}$ & 4 \\
Number of hidden layer & 1 & $\mathbf{1}$ & 1 \\
Number of hidden neurons & 1 & $\mathbf{1}$ & 1 \\
Number of output neurons & 1 & $\mathbf{1}$ & 1 \\
MSE value & 0.0446 & $\mathbf{0 . 0 3 8 4}$ & 0.0468 \\
\hline
\end{tabular}

Table 9. The confusion matrix of training dataset in one hidden neuron in LM algorithm

\begin{tabular}{ccc}
\hline Data category & Low & High \\
\hline Low & $13(\mathrm{ep})$ & $4(\mathrm{sn})$ \\
High & $1(\mathrm{sp})$ & $50(\mathrm{en})$ \\
\hline
\end{tabular}

Modeling of agarwood oil compounds based on linear regression and ANN ... (Noratikah Zawani Mahabob) 
Table 10. The MLP classification performance measures for training dataset

\begin{tabular}{cc}
\hline Parameter & Value \\
\hline Accuracy & $92.6 \%$ \\
Sensitivity & $76.5 \%$ \\
Specificity & $98 \%$ \\
Precision & $92.9 \%$ \\
\hline
\end{tabular}

\section{CONCLUSION}

This study represents two models, stepwise regression and multilayer perceptron, for use in the classification agarwood oil quality. Four independent variables (compounds) were selected as the factors to agarwood oil. The compounds were $\beta$-agarofuran, $\Upsilon$-Eudesmol, Longifolol and Eudesmol A linear relationship for agarwood oil was obtained at $\mathrm{Y}=0.031742 \mathrm{X}_{1}+0.021556 \mathrm{X}_{4}+0.10766 \mathrm{X}_{5}-0.25592 \mathrm{X}_{7}+$ 1.7337 with values of $\mathrm{R}^{2}$ and $\mathrm{R}^{2}$ Adj is $68.7 \%$ and $67.4 \%$. The three training algorithms in MLP were successfully implemented as classifiers in order to classify agarwood oil into high and low quality. It was found that the network architecture (4-1-1) with referred to 4 neurons in input layer, 1 hidden neuron in a single hidden layer and 1 neuron in output layer was most suitable for modeling agarwood oil in this study. The MLP with the LM algorithm using one hidden neuron outperformed others in term of accuracy and mean square error (MSE). This technique will benefit to the agarwood oil industry especially in terms of its grading system.

\section{ACKNOWLEDGEMENTS}

This research is funded by Institute of Research Management and Innovation (IRMI), Universiti Teknologi MARA (UiTM) Kampus Pasir Gudang, Malaysia under Grant No: 600-IRMI/FRGS 5/3 (224/2019).

\section{REFERENCES}

[1] D. P. Wibowo, Y. Febriani, H. Riasari, and D. L. Aulifa, "Chemical composition, antioxidant and antibacterial activities of the essential oils of medicinal plant Cymbopogonnardus from Lembang West Java," Research Journal of Chemisty and Environment, vol. 22, no. 1, pp. 1-4, 2018.

[2] L. G. De Toledo et al., "Essential oil of Cymbopogon nardus (L.) Rendle: A strategy to combat fungal infections caused by Candida species," International Journal of Molecular Sciences, vol. 17, no. 8, 2016, Art. no. 1252, doi: 10.3390/ijms17081252.

[3] N. Ismail, N. A. M. Ali, M. Jamil, M. H. F. Rahiman, S. N. Tajuddin, and M. N. Taib, "A Review Study of Agarwood Oil and Its Quality Analysis," Jurnal Teknologi, vol. 68, no. 1, pp. 37-42, 2014, doi: $10.11113 /$ jt.v68.2419.

[4] M. H. Haron, M. N. Taib, N. Ismail, N. A. Mohd Ali, and S. N. Tajuddin, "Statistical analysis of agarwood oil compounds based on GC-MS data," 2018 9th IEEE Control and System Graduate Research Colloquium (ICSGRC), 2019, pp. 27-30, doi: 10.1109/ICSGRC.2018.8657571.

[5] N. Ismail, M. H. F. Rahiman, M. N. Taib, M. Ibrahim, S. Zareen, and S. N. Tajuddin, "A review on agarwood and its quality determination," 2015 IEEE 6th Control and System Graduate Research Colloquium (ICSGRC, 2016), pp. 103-108, DOI:10.1109/ICSGRC.2015.7412473.

[6] S. Akter, M. T. Islam, M. Zulkefeli, and S. I. Khan, "Agarwood Production-A Multidisciplinary Field to be Explored in Bangladesh," International Journal of Pharmaceutical and Life Sciences, vol. 1, no. 4, pp. 1-11, 2013, doi: 10.3329/ijpls.v2i1.15132.

[7] N. S. Zubir et al., "Pattern Classifier of Chemical Compounds in Different Qualities of Agarwood Oil Parameter using Scale Conjugate Gradient Algorithm in MLP," 2017 IEEE 13th International Colloquium on Signal Processing \& its Applications (CSPA), 2017, pp. 10-12, doi: 10.1109/CSPA.2017.8064917.

[8] P. E. Keller, "Mimicking biology: Applications of cognitive systems to electronic noses," Proceedings of the 1999 IEEE International Symposium on Intelligent Control Intelligent Systems and Semiotics (Cat. No.99CH37014), 1999, pp. 447-451, doi: 10.1109/ISIC.1999.796696.

[9] M. A. A. Aziz, N. Ismail, I. M. Yassin, A. Zabidi, and M. S. A. M. Ali, "Agarwood oil quality classification using cascade-forward neural network," 2015 IEEE 6th Control and System Graduate Research Colloquium (ICSGRC), 2016, pp. 112-115, doi: 10.1109/ICSGRC.2015.7412475.

[10] N. Ismail, M. H. F. Rahiman, M. N. Taib, N. A. M. Ali, M. Jamil, and S. N. Tajuddin, "Application of ANN in agarwood oil grade classification," 2014 IEEE 10th International Colloquium on Signal Processing and its Applications, 2014, pp. 216-220, doi: 10.1109/CSPA.2014.6805751.

[11] N. Ismail, M. H. F. Rahiman, M. N. Taib, N. A. M. Ali, M. Jamil, and S. N. Tajuddin, "Classification of the quality of agarwood oils from Malaysia using Z-score technique," 2013 IEEE 3rd International Conference on System Engineering and Technology, 2013, pp. 78-82, doi: 10.1109/ICSEngT.2013.6650147.

[12] M. A. Nor Azah, S. S. Husni, J. Mailina, L. Sahrim, J. A. Majid, and Z. Mohd Faridz, "Classification of agarwood (gaharu) by resin content,” Journal of Tropical Forest Science, vol. 25, no. 2, pp. 213-219, 2013. 
[13] H. Jantan, I. M. Yassin, A. Zabidi, and N. Ismail, "Differentiation of Agarwood Oil Quality Using Support Vector Machine (SVM)," Journal of Engineering and Applied Sciences, vol. 12, no. 15, pp. 3810-3812, 2017, doi: 10.3923/jeasci.2017.3810.3812.

[14] K. A. A. Kamarulzaini, N. Ismail, M. H. F. Rahiman, M. N. Taib, N. A. M. Ali, and S. N. Tajuddin, "Evaluation of RBF and MLP in SVM kernel tuned parameters for agarwood oil quality classification," 2018 IEEE 14th International Colloquium on Signal Processing \& Its Applications (CSPA), 2018, pp. 250-254, doi: 10.1109/CSPA.2018.8368721.

[15] N. Ismail, "ANN Modeling for Agarwood Oil Significant Compounds for Oil Quality Discrimination," PhD Dissertation, Faculty of Electrical Engineering, Universiti Teknologi Mara (UiTM), 2014.

[16] A. Rabiee Kenaree and S. Fatemi, "Application of Artificial Neural Network in Simulation of Supercritical Extraction of Valerenic Acid from Valeriana officinalis L.," International Scholarly Research Notices, vol. 2012, pp. 1-7, 2012, Art. no. 572421, doi: 10.5402/2012/572421.

[17] A. Moghadassi, S. M. Hosseini, F. Parvizian, I. Al-Hajri, and M. Talebbeigi, "Predicting the supercritical carbon dioxide extraction of oregano bract essential oil," Songklanakarin Journal of Science and Technology, vol. 33, no. 5, pp. 531-538, 2011.

[18] A. Zabidi, L. Y. Khuan, W. Mansor, I. M. Yassin, and R. Sahak, "Detection of infant hypothyroidism with mel frequency cepstrum analysis and multi-layer perceptron classification," 2010 6th International Colloquium on Signal Processing \& its Applications, 2010, pp. 140-144, doi: 10.1109/CSPA.2010.5545331.

[19] N. Shah and S. Jain, "Detection of Disease in Cotton Leaf using Artificial Neural Network," 2019 Amity International Conference on Artificial Intelligence (AICAI), 2019, pp. 473-476, doi: 10.1109/AICAI.2019.8701311.

[20] K. Pimparkar, R. Lulla, P. Rathod, V. Anirudh, and S. G. Dedgaonkar, "Document Management using Artificial Neural Network," 2019 International Conference on Communication and Electronics Systems (ICCES), 2019, pp. 897-900, 10.1109/ICCES45898.2019.9002062.

[21] A. Salam, A. El Hibaoui, and A. Saif, "A comparison of activation functions in multilayer neural network for predicting the production and consumption of electricity power," International Journal of Electrical and Computer Engineering (IJECE), vol. 11, no. 1, pp. 163-170, 2021, doi: 10.11591/ijece.v11i1.pp163-170.

[22] B. B. Bezabeh and A. D. Mengistu, "The effects of multiple layers feed-forward neural network transfer function in digital based ethiopian soil classification and moisture prediction," International Journal of Electrical and Computer Engineering (IJECE), vol. 10, no. 4, pp. 4073-4079, 2020, doi: 10.11591/ijece.v10i4.pp4073-4079.

[23] A. Özdemir, U. Yavuz, and F. A. Dael, "Performance evaluation of different classification techniques using different datasets," International Journal of Electrical and Computer Engineering (IJECE), vol. 9, no. 5, pp. 3584-3590, 2019, doi: 10.11591/ijece.v9i5.pp3584-3590.

[24] S. A. Taylor and M. Li, "Notes for Data Analysis," California State University, pp. 1-167, 2008.

[25] I. M. M. Ghani and S. Ahmad, "Stepwise multiple regression method to forecast fish landing," Procedia - Social and Behavioral Sciences, vol. 8, pp. 549-554, 2010, doi: 10.1016/j.sbspro.2010.12.076.

[26] M. Noryani, S. M. Sapuan, M. T. Mastura, M. Y. M. Zuhri, and E. S. Zainudin, "Material selection of natural fibre using a stepwise regression model with error analysis," Journal of Materials Research and Technology, vol. 8, no. 3, pp. 286-2879, 2019, doi: 10.1016/j.jmrt.2019.02.019.

[27] M. Sokolova and G. Lapalme, "A systematic analysis of performance measures for classification tasks," Information Processing \& Management, vol. 45, no. 4, pp. 427-437, 2009, doi: 10.1016/j.ipm.2009.03.002.

\section{BIOGRAPHIES OF AUTHORS}

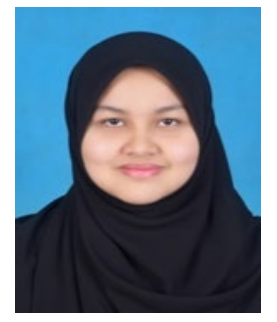

Noratikah Zawani Mahabob was born in Malaysia, on June 1996. She received her B. Eng (Hons) of Electronic Engineering from Universiti Teknologi MARA (UiTM). Currently, she is a postgraduate student at Faculty of Electrical Engineering, Universiti Teknologi MARA (UITM) Shah Alam Malaysia.

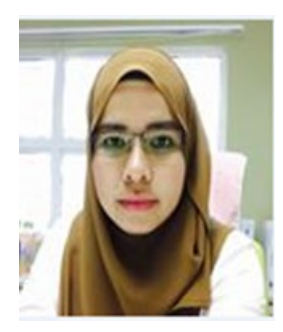

Zakiah Mohd Yusoff is a senior lecturer who is currently working at UITM Pasir Gudang. She received the B. ENG in Electrical Engineering and PhD In Electrical Engineering from UITM Shah Alam, in 2009 and 2014, respectively. In Mei 2014, she joined UITM Pasir Gudang as a teaching staff. Her major interests include process control, system identification, and essential oil extraction system 


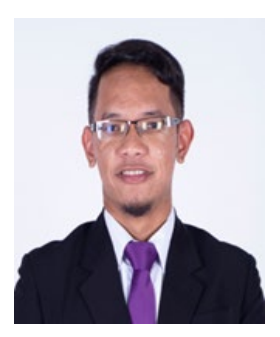

Aqib Fawwaz Bin Mohd Amidon was born in Malaysia, on September 1996. He received his B. Eng. (Hons) of Electronic Engineering from Universiti Teknologi MARA (UiTM). He is currently a Software Engineer at Greatech Technology Berhad and at the same time as part time postgraduate student's at Faculty of Electrical Engineering, Universiti Teknology MARA, UiTM Shah Alam, Malaysia

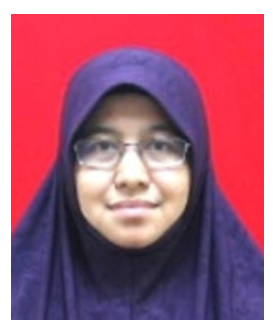

Nurlaila Ismail received her PhD in Electrical Engineering from Universiti Teknologi MARA, Malaysia. She is currently a senior lecturer at the Faculty of Electrical Engineering, Universiti Teknologi MARA, Malaysia. Her research interests include advanced signal processing and artificial intelligence.

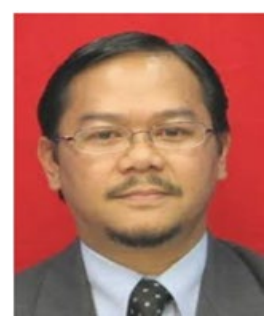

Haji Mohd Nasir Taib received his PhD from UMIST, UK. He is a Senior Professor at Universiti Teknologi MARA (UiTM). He heads the Advanced Signal Processing Research Group at the Faculty of Electrical Engineering, UiTM. He has been a very active researcher and over the years had author and/or co-author many papers published in refereed journals and conferences. 